\title{
FIKIH INDONESIA: \\ EPISTEMOLOGI SOSIO-KULTURAL
}

\author{
Mahfudz Junaedi \\ Universitas Sains Al Qur'an (UNSIQ) Wonosobo \\ email: junaedimahfudz65@gmail.com
}

\begin{abstract}
Fiqh presents with the presence of Islamic studies that then is being practiced in the society. Fiqh epistemology in Indonesia as the Islamic law has characters and Indonesian special features either written or unwritten in the book of law. All this time, fiqh is still attached with cultural trademark and Middle-Eastern tradition. The socio-cultural condition of Indonesia society, however, gives contribution and historical setting of Islamic law in Indonesia so that figh reformation that is identical with Indonesian is the demand and the dynamic of modern Muslims nowadays. Fiqh as a necessity must be kept in touch with science as the integral part and takes into account to solve the modern problems through the update thought to form the Indonesian fiqh. The indigenization of fiqh holistically uses the various patterns and methods. The demand of updating fiqh already causes the reshuffle of fiqh epistemology from teosentrisme epistemology to antroposentrisme epistemology. Therefore, the contextualization of figh always follows the socio-cultural and development of human knowledge with various typology characteristics of society that are formed by its socio-culture and the culture around it. Hence, figh will be fresher than before to answer the new problems in modern society in Indonesian context.
\end{abstract}

Key word: Fiqh Indonesia, epistemology, contextualization.

\section{Pendahuluan}

Fikih sebagai hukum yang hidup (living law) di Indonesia sesungguhnya memiliki sejarah yang sangat panjang. Akar geneologinya dapat ditarik jauh kebelakang ketika pertama kali Islam masuk ke Indonesia, dan hukum Islam (fikih) sudah dipraktekkan bersamaan dengan masuknya Islam di Indonesia. ${ }^{1}$ Akulturasi dan adaptasi dengan budaya dan adat setempat tidak dapat dihindari atas

1 Azyumardi Azra, Jaringan Ulama Timur Tengah dan Kepulauan Nusantara Abad XVII dan XVIII (Bandung: Mizan, 1994), hlm., 24-36, lihat juga M. Atho Mudzhar, Fatwa-FatwaMajelis Ulama Indonesia (Jakarta : INIS, 1993, hlm., 12 
perubahan dan pembaruan hukum Islam yang memiliki karakter keindonesiaan $^{2}$. Tradisi (adat) budaya masyarakat Indonesia telah memberikan andil terhadap pembaharuan dan pemikiran hukum Islam di Indonesia baik pra kemerdekaan dan pasca kemerdekaan Indonesia.

Untuk merubah paradigma hukum Islam sebagai salah satu ciri utama yang memungkinkan terjadinya pembaharuan hukum Islam adalah wataknya yang non-mazhab yang dipengaruhi oleh kemajuan dan plularitas sosial-budaya serta politik pada suatu masyarakat atau negara. Hal ini juga dapat dianalisis keadaan awal perkembangan hukum Islam dengan mengambil setting keadaan wilayah, sosiokultural masyarakat sebagaimana yang dikembangkan oleh para pendiri mazhab fikih seperti, di Hijaz, Irak, dan Mesir. Jelas sekali peran dan pengaruh tempat termasuk elemen-elemen sosial-budaya, dan politik telah membawa para fuqaha' dalam merumuskan mazhab fikih. Demikian juga, pembaruan fikih di Indonesia tidak dapat dilepaskan dari paradigma pemikiran mazhab fikih klasik di atas, dengan munculnya gagasan fikih mazhab Indonesia, sebagai interalasi antara fikih, negara, dan perubahan sosial-kultural masyarakat Indonesia.

Dalam perspektif historis, dinamika pemikiran hukum Islam di Indonesia telah menunjukkan satu fenomena transformatif dan remedialis, walaupun masih tampak kuat nuansa paralisme di dalamnya, sehingga kesan tautologinya masih ada. Setidaknya pemikiran pembaruan hukum Islam di Indonesia seperti bola salju yang menggelinding dan melaju dengan pasti menuju arah konstruksi berbagai tipe karakter hukum Islam konteks Indonesia ${ }^{3}$.

Meanstrem pemikiran dan pemahaman yang didasarkan pada alQur'an dan Sunnah Nabi dengan mengunakan metodologi yang benar dan dapat dipertanggungjawabkan merupakan interpretasi yang dalam hukum Islam disebut dengan fikih. ${ }^{4}$ Fikih Islam, sejak pertama kali lahir telah berinteraksi dengan realitas sekitar masyarakat yang mana

\footnotetext{
${ }^{2}$ Hasbi ash-Shiddiqiey, Syariah Islam Menjawab Tantangan Zaman (Jakarta: Bulan Bintang, 1996), hlm., 8-9.

${ }^{3}$ Fiqh merupakan hasil dialektika rasional antara nilai-nilai syari'ah yang terkandung dalam al-Qur'an dan as-Sunnah dengan memperhatikan pada realitas masyarakat dan kondisi objektif ruang waktu yang dihadapi. Mengenai kajian istilah fikih, lihat buku Imran Ahsan Khan Nyazee, Theories of Islamic Law: the Methodology of Ijtihad (Islamabad: Islamic reseach Institute press, 1994), hlm. 20 26. Agus Moh. Najib, Evolusi Syari'ah : Ikhtiar Mahmoud Mohamed Taha bagi Pembentukan Hukum Islam Kontemporer (Yogyakarta: Pesantren Nawesea Press, 2007), hlm. 29.

${ }^{4}$ Mengenai kajian Kitab Klasik yang berlaku di Indonesia, baca Martin Van Bruinessen, Kitab kuning pesantren dan tarekat (Bandung, Penerbit Mizan, 1999), hlm. 67-68
} 
fikih dirumuskan untuk diterapkan, dan realitas ulama yang memikirkan dan merumuskan. ${ }^{5}$ Misi utama fikih adalah untuk menyampaikan pesan wahyu yang disesuaikan dengan realitas peradaban manusia untuk merespon dan menjawab tantangan zaman (shalih li kulli zaman wa makan). ${ }^{6}$ Peran interpretasi dalam memahami nash-nash illahi untuk dapat dioperasional menjadi pesan insani dalam proses perjalannya telah mengalami pasang surut pemikiran untuk mengantar fikih sebagai produk hukum Islam yang dianggap telah menjadi syari'ah.

\section{Eksistensi Fikih Indonesia}

Perkembangan pemikiran fikih, sejak pertama Islam masuk di Indonesia, telah dikenalkan berbagai aliran fikih, misalnya: Syekh Abdurrauf Singkel (1643-1693 M), Syekh Arsyad al-Banjari, Syekh Ahmad Khatib al-Minangkabau, Syekh Nawawi Banten (1230H/1813M - 1314H/1897 M), KH. Hasyim Asy'ari (1871-1947M), KH. Ahmad Dahlan $\left(1868-1923\right.$ M) ${ }^{7}$ Di antara pemikir hukum Islam kontemporer yang memberi andil besar pada mazhab fikih Indonesia, adalah M.T. Hasbi ash-Shiddiqi (1905-1975 M), Hazairin (1906-1975 M), Munawir Syadzali (1925-2006 M), KH. Sahal Mahfudz (1937 Msekarang) dan KH. Ali Yafie (1926 M - sekarang), Masdar F. Mas'udi (1954 M - sekarang), ${ }^{8}$ KH. Abdurrahman Wahid (Gus Dus - 1940 2009) $)^{9}$. Para pencetus dan gagasan pembaruan hukum Islam di Indonesia menfokuskan pada bidang tertentu dengan muara pada pembentukan hukum Islam yang sesuai dengan konteks sosial budaya dan adat Indonesia.

${ }^{5}$ Abdul Mustaqim, Epistemologi Tafsir Kontemporer (Yogyakarta: LKiS, 2010), hlm. 53-55; Ainurrofiq (ed.), Mazhab Jogja: Menggagas Paradigma Ushul Fiqh Kontemporer (Yogyakarta, LKiS, 2006), hlm. 230-248.

${ }^{6}$ Abdul Mustaqim, Epistremologi Tafsir Kontemporer (Yogyakarta: LKiS, 2010), hlm. 53-55; Ainurrofiq (ed.), Mazhab Jogja: Menggagas Paradigma Ushul Fiqh Kontemporer (Yogyakarta, LKiS, 2006), hlm. 230-248.

7 Nama-nama tersebut sebagai pembaru pemikiran hukum Islam dalam konteks sosial budaya Indonesia yang berkembang pada abad ke 19, karya-karya fikih mereka dijadikan rujukan dalam pergumulan pemikiran umat Islam di Indonesia.

${ }^{8}$ Mahsun Fuad, Hukum Islam Indonesia, Dari Nalar Parsipatoris Hingga Emansipatoris (Yogjakarta : LKiS, 2005), hlm. 75.

${ }^{9}$ Muhammad Rifa, Gus Dus, KH Abdurrahman Wahid Biografi Singkat 1940-2009 (Jakarta: Ar-Ruzz Media, 2010) hlm. 20, lihat, Greg Barton, Biografi Gus Dur: The Authorized Biography of Abdurrahman Wahid, terj. Lie Hua (Yogyakarta: :LKiS, 2010), hlm., 44-45, lihat, Moh. Dahlan, Paradigma Ushul Fiqh Multikultural Gus Dus (Yogyakarta: Kaukaba Dipantara, 2013), hlm., 15-51. 
Setting sejarah sosial pemikiran fikih (hukum Islam) di atas telah mendorong Hazairin, ${ }^{10}$ untuk membentuk fikih mazhab nasional dalam perkembangan berikutnya berubah nama menjadi fikih mazhab Indonesia - dengan mengambil pemikiran fikih Syafi'i. Apabila dilihat dari permasalahan umat Islam di Indonesia adalah masalah hukum yang mana karakteristik fikih berbeda dengan unsur keimanan dan keislaman lainnya. Hazairin berkeyakinan bahwa fikih akan selalu mengikuti dinamika dan perubahan umat Islam, sehingga gagasan fikih mazhab Indonesia sangat relevan dengan konteks umat Islam di Indonesia. ${ }^{11}$ Dengan demikian, pintu ijtihad dalam hukum Islam tidak perlu tertutup dan senantiasa terbuka seiring dengan perubahan masyarakat. Dari titik awal inilah yang dijadikan alasan dan pertimbangan akan perlunya konstruksi mazhab baru yang relevan dengan kondisi aktual umat Islam di Indonesia. Dalam konstruk bangunan fikih mazhab Indonesia, eksistensi hukum adat tidak dapat dipisahkan dalam turut serta pembentukan fikih mazhab Indoneesia yang akhirnya sebagai bagian integral dalam pembentukan hukum nasional. ${ }^{12}$

Pemikiran (baca-ijitihad) Hazairin dalam membentuk fikih mazhab Indonesia, khususnya dalam menemukan hukum kewarisan yang bercorak sistem kekeluargaan bilateral yang mengkompromikan dengan hukum adat masyarakat Muslim di Indonesia, ${ }^{13}$ pada tataran analisis menggunakan pendekatan antropologi, perubahan sosial merupakan suatu hal baru apabila dilihat pada zamannya dan konteks budaya keindonesiaan. Walaupun produk pemikiran Hazairin telah melahirkan produk fikih atau hukum di Indonesia yang lebih fresh dengan pendekatan antropologi sesuai dengan watak dan karakter

10 Mengenai biografi Hazairin, dapat dilihat pada Hasan Shadily (ed.) Ensiklopedi Indonesia, jilid 1 (Jakarta : Ikhtiar Baru, 1980), hlm. 120; Entri Hazairin, dalam Tempo (ed.), Apa dan Siapa Orang-orang Indoensia 1981-1982. Cet. 1 (Jakarta: Grafity Press, 1981), hlm. 187-189; Suyuti Thalib, Pembaharuan Hukum Islam di Indonesia: In Memorian Prof. Mr. Dr. Hazairin (Jakarta: UI Press, t.t.), hlm. 46-48.

11 Syamsul Wahidin dan Abdurrahman, Perkembangan Ringkas Hukum Islam di Indonesia (Jakarta: Akademika Pressindo, 1984), hlm. 87-88; KN. Sofyan Hasan dan Warkum Sumitro, Dasar-Dasar Memahami Hukum Islam di Indonesia (Surabaya: Usaha Nasional, 1994), hlm. 102-103.

${ }^{12}$ Hazairin, Demokrasi Pancasila (Jakarta : Tintamas, 1973), hlm. 18-20

${ }^{13}$ Sebagai bagian integral dalam pembentukan hukum Nasional, seperti munculnya UU No. 1 Tahun 1974 tentang Perkawinan, UU Peradilan Agama, Kompilasi Hukum Islam (KHI) merupakan bagian dari pembaharuan hukum Islam di Indonesia, sehingga pemikiran Hazairin memberikan sumbangsih dalam pembentukan hukum Nasional sesuai dengan hukum yang berkembangan di Indonesia. Lihat, Sofyan Hasan dan Warkum Sumitro, Dasar-dasar Pembentukan Hukum Islam (Jakarta : Rajawali Grafindo Persada, 2003), hlm. 24-26. 
masyarakat Indonesia. Dalam paradigma ilmu pengetahuan kontemporer, pemikiran Hazairin juga perlu dikritisi kembali dengan menggunakan pisau analisis dan pendekatan interdisipliner termasuk pada hermeneutika dan paradigma integrasi-interkoneksi keilmuan modern. Paradigma fikih klasik yang dihasilkan oleh para mujtahid khususnya dalam menafsirkan ayat-ayat kewarisan bukan suatu hasil final dan mutlak kebenarannya, karena fikih itu sendiri merupakan produk ilmu pengetahuan yang erat berhubungan dengan peradaban dan paradigma keilmuan yang mengitarinya. Dalam ini, fikih sebagai ilmu atau metode sebagai konstruk teori pengetahuan dan pemahanan harus disesuaikan perkembangan ilmu pengetahuan manusia kontemporer. Demikian juga dengan fikih sebagai produk hukum (jurisprodensi) dan norma hukum dalam aplikasiya akan berhadapan dengan perubahan sosial, sehingga produk hukum tersebut akan selalu tertinggal dari kondisi aktual di masyarakat. Merekonstruksi pemahaman dan penafsiran ulang ${ }^{14}$ terhadap sumber hukum Islam (alQur'an dan as-Sunnah) merupakan suatu keniscayaan dalam perkembangan kontemporer sekarang ini dengan menggunakan pendekatan interdisipliner. ${ }^{15}$

Selama ini pemahaman fikih dan termasuk usul fikih lebih pada tataran literalis bukan pada aplikasi sesuai dengan konteks. Dengan demikian, teks ayat-ayat waris perlu dikontekkan sesuai dengan transpormasi sosial, keadilan dan perkembangan umat Islam. Pendekatan kajiannya lebih difokuskan pada filsafat ilmu dengan kerangka teori pada perubahan paradigma termasuk di dalamnya adalah perubahan epistemologi, menurut hemat penulis, perubahan epistemologi fikih harus dilakukan secara integral-interkonektif terhadap disiplin keilmuan yang ada, sehingga produk fikih tidak stagnan, tetapi justru seiring dan sejalan dengan perkembangan ilmu pengetahuan kontemporer. Untuk itu, metode yang dipergunakan menjawab problem filsafat hukum Islam adalah melakukan interkonektif, integratif deduktif, induktif, dan komperatif.

${ }^{14}$ Akbar S. Ahmed, membedah Islam (Bandung: Pustaka, 1997), hlm. 129130; dan H. M. Atho Mudzhar, Membaca Gelombang Ijtihad.... hlm. 66-67

${ }^{15}$ M. Amin Abdullah (ed.) Antologi Studi Islam : Teori dan Metodologinya (Yogjakarta: Sunan Kalijaga Press, 2000), hlm. 239-313; dan Peter Connolly (ed.) Aneka Penekatan Studi Agama (Yogjakarta : LKiS, 2011), hlm. 15-62, 149-190, 271 314; dan M. Amin Abdullah, Islamic Studies di Perguruan Tinggi : Pendekatan Integratif-Interkonektif (Yogjakarta: Pustaka Pelajar, 2006), hlm. 115-146. 


\section{Epistemologi Fikih Indonesia}

Setidaknya ada tiga model pemikiran tentang pembaruan fikih di Indonesia harmonisasi dengan sosio-kultural budaya dan adat. Pertama, pemikiran fikih Indonesia tidak dapat dilepaskan dari pemikiran yang telah dilakukan oleh para tokoh, akademisi yang pernah memunculkan gagasan tentang fikih Indonesia. Kedua, Pemikiran tentang pembentukan fikih Indonesia juga tidak dapat dilepaskan dari dealitika proses metodologi hukum Islam untuk diaplikasikan dalam konteks, ruang dan waktu keindonesiaan dengan prinsip şaleh li kulli makan wa zaman ${ }^{16}$, merupakan prinsip yang harus dikembangkan dalam pelaksanaan maqashid syari'ah (tujuan syari'ah) dalam mencapai kemaslahatan ummat. Ketiga, originalitas pemikiran hukum Islam dengan menggunakan ilmu bantu lain secara holistik, sehingga relevan dengan karakter sosio-budaya dan adat Indonesia.

Fikih Indoneaia secara kritis-paradikmatik sebagai ijtihad baru untuk membentuk fikih Indonesia dalam kerangka membangun legalisasi hukum positif melalui yurisprodensi pengadilan agama, peraturan perundang-undangan di Indonesia yang berhubungan kebutuhan umat Islam di Indonesia. Seperti pemikiran dan kajian yang dilakukan Hasbi ash-Shiddieqy ${ }^{17}(1905$ - 1975) untuk membentuk karakter fikih Indonesia harus sesuai dengan kepribadian Indonesia, lebih lanjut Hasbi berupaya untuk menginkorporasikan serta mempertimbangkan suatu unsur struktur kebudayaan (adat) ke dalam rumusan metodologi hukum Islam dengan menggunakan pendekatan mashlahah yang diimplementasikan dalam mengatasi persoalanpersoalan hukum yang ada setidaknya cukup meyakinkan anggapan dasar menuju ke arah ligislasi hukum Islam.

${ }^{16}$ Prinsip universalisme hukum Islam merupakan keinginan umat Islam untuk selalu mendialogkan Al-Qur'an sebagai teks yang terbatas dengan problem sosial kemanusiaan dan hukum yang tak terbatas. Meskipun Al-Qur'an turun dimasa salalu dengan konteks sosial, budaya dan lokalitas tertentu, ia mengandung nilai-nilai universal yang akan selalu relevan untuk setiap zaman dan tempat. Demikian juga fiqh atau hukum Islam akan selalu lekat dengan konteks sosial dan lokalitas yang melingkupinya. Diskursus di seputar penafsiran Al-Qur'an merupakan diskursus yang tidak mengenal kata usai. Lihat Amin Abdullah, "Kata Pengantar" dalam Sahiron Syamsuddin dkk (ed.), Hermeneutika al-Qur'an : Madzhab Yogya (Yogyakarta: Islamika, 2003), hlm. xx

${ }^{17}$ Berbagai studi dan penelitian yang coba memotret pemikiran, aktivitas, karya ilmiah, dan konstribusi Hasbi dalam idang keilmuan Islam telah banyak dilakukan. Karya representatif yang cukup untuk memberikan pemahaman akan potret diri, dan seluk-beluk pemikiran, serta karya ilmiahnya dapat dilihat pada Nourouzzaman Siddiqi, Fiqh Indonesia: Penggagas dan Gagasannya (Yogjakarta : Pustaka Pelajar, 1997), hlm. 102. 
Pemikiran dan kajian fikih mazhab Indonesia Hazairin ${ }^{18}(1906-$ 1975), merupakan upaya menyatukan nilai-nilai adat ke dalam sistem hukum nasional yang menyeluruh sehingga legalitas fikih memiliki kepastian hukum Islam terutama dalam masalah-masalah perkawinan dan hukum waris bagi ummat Islam. Hazairin melakukan interpretasi terhadap nash qath'i merupakan bentuk buah pemikiran yang cukup berani sebagai ahli hukum adat dan bukan seorang ulama/ahli fikih dalam merumuskan kembali tentang konsep "mawali". Pemikiran Hazairin ini tidak dapat dilepaskan dari paradigma fikih di Indonesia yang lebih banyak menggunakan fikih mazhab Syafi'i, dan karekter fikih mazhab Syafi'i paralel dengan nilai-nilai adat Indonesia. Dalam perspektif politik hukum di Indonesia, Hazairin memandang bahwa teori receptie sebagai teori iblis dan propaganda kolonial untuk menghilangkan pengaruh hukum Islam pada masyarakat Indonesia, dan menggunakan hukum-hukum kolonial.

Pemikiran lain dalam upaya untuk membentuk format baru fikih Indonesia dengan cara reaktualisasi (kontestualisasi) terhadap ajaran Islam sebagaimana yang dilakukan oleh Munawir Sjadzali ${ }^{19}$, sebagai upaya reinterpretasi doktrin ajaran Islam terutama dalam masalahmasalah kewarisan Islam. Bahwa tidak berjalannya hukum waris Islam dikalangan ummat Islam, karena hukum waris Islam belum memberikan keadilan secara kontektual ummat Islam terutama dalam prinsip keadilan. Hukum waris Islam lebih banyak dilakukan secara pre-emptive, yaitu membagi harta waris dengan cara dihibahkan terlebih dahulu sebelum meninggal dunia, kondisi ini dianggap sebagai cara mengelabuhi masalah hukum waris yang tidak sesuai dengan konteks dan rasa keadilan manusia. Munawir Sjadzali mengupayakan interpretasi ulang ayat-ayat waris untuk menemukan kemasalahatan dan keadilan manusia dan inilah yang hendak dicapai oleh hukum Islam.

Pemikiran dan pembaruan hukum Islam A. Qodri Azizy ${ }^{20}$ dengan menawarkan pemikiran hormanisasi dan sinkronisi hukum yang telah berlaku di Indonesia serta memperhatikan atas perubahan-

18 Mengenai biografi Hazairin dapat dilihat pada Hasan Shadily (ed.), Ensiklopedi Indonesia, jilid 1 (Jakarta : Ikhtiar Baru, 1980), hlm. 346; Lihat juga, Entri Hazairin, dalam Tempo (ed.), Apa dan Siapa Orang-orang Indonesia 1981 1982 Cet. 1 (Jakarta: Grafity Press, 1981), hlm. 110; Lihat, Sayuti Thalib, Pembaharuan Hukum Islam di Indonesia; In Memorian Prof. Mr. Dr. Hazairin (Jakarta : UI Press, t.t.), hlm. 68-70.

${ }^{19}$ Munawir Sjadzali, “Reaktualisasi Ajaran Islam, dalam Iqbal Abdur Rauf Saimina (ed), Polemik Reaktualisasi Ajaran Islam (Jakarta : Pustaka Panjima, 1988), hlm. 2 .

${ }^{20}$ Lihat. A. Qodri Azizy, Eklektisisme Hukum Nasional : Kompetisi Antara Hukum Islam dan Hukum Umum (Yogjakarta: Gama Media, 2002), hlm. 2-3 
perubahan sosial yang sangat dinamis di masyarakat modern. A. Qodri berupaya mempertemukan hukum Islam dan hukum umum menjadi produk hukum nasional yang dapat dipergunakan oleh umat Islam dengan memperhatikan pada aspek sosial-budaya masyarakat setempat. Menurutnya, sebuah hasil ijtihad tanpa peran negara tidak akan memiliki kekuatan apapun, sehingga hasil ijtihad sebagai produk lokal atau sesuai dengan konteks adat istiadat ( $a l$ - 'Urf) tidak dapat berjalan tanpa adanya peran dan dukungan dari negara.

\section{Tawaran Metodologi Baru: fresh Ijtihad .}

Pemikiran dan pembaruan hukum Islam - di Indonesia - tidak dapat dilepaskan dari kajian teori sistem menggunakan pendekatan filsafat ilmu. Dengan filsafat ilmu subjek dan objek sasarannya ilmu (pengetahuan) memperhatikan secara keseluruhan, ruang lingkup filsafat ilmu meliputi dua pokok bahasan: Pertama, sifat pengetahuan ilmiah memiliki kaitan erat dengan filsafat pengetahuan atau epistemologi, serta memiliki syarat-syarat dan bentuk-bentuk pengetahuan. Kedua, membahas cara-cara mengusahakan pengetahuan ilmiah, memiliki kaitan erat dengan logika atau metodologi. ${ }^{21}$

Filsafat pengetahuan (epistemologi) dengan menggunakan pemikiran filsafat ilmu Thomas S. Kuhn yang membahas persoalan pergeseran paradigma (paradigm shift) dalam ilmu pengetahuan. ${ }^{22}$ Pembahasan paradigm shift ini menjadi penting untuk mengkaji unsurunsur anomali dalam epistemologi fikih Indonesia. Pembahasan fikih sangat berhubungan dengan epistemologi makna dan kebenaran dalam memahami fikih. ${ }^{23}$ Dalam memahami teks sebagai sumber hukum Islam pembahasan dan aplikasinya menggunakan hermeneutika, ${ }^{24}$ karena dengan hermenutika akan didapatkan pemahanan dan penafsiran

21 KoentoWibisono Siswomihardjo, "Ilmu Pengetahuan Sebuah Sketsa Umum mengenai Kelahiran dan Perkembangannya sebagai Pengantar untuk Memahami Filsafat Ilmu" dan Imam Wahyudi, "Ruang Lingkup dan Kedudukan Filsafat Ilmu", dalam Tim Dosen Filsafat Ilmu UGM (Penyusun), Filsafat Ilmu : Sebagai Dasar Pengembangan Ilmu Pengetahuan (Yogjakarta: Liberty, 2001), hlm. 11-44; lihat, Louis O. Kattsoff, Pengantar Filsafat (Elements of Philosophy) alih bahasa, Soejono Soemargono (Yogjakarta: Tiara Wacana Yogja, 2004), hlm. 159184.

${ }^{22}$ Thomas S. Kuhn, The Structure of Scientific Revolution (Chicago: The University of Chicago Press, 1970), hlm. 84-85.

${ }^{23}$ Ali Harb, Hermeneutika Kebenaran (Yogjakarta: LKiS, 2003), hlm. 121170.

${ }^{24}$ Richard E. Palmer, Hermeneutics Interpretation Theory in Schleirmacher, Dilthey, Heidegger, and Gadamer (Northwesttern: University Press Evanston, 1969), hlm. 83-231 
terhadap sumber hukum Islam yang bersumber dari teks Al-Qur'an dan Hadis sesuai dengan konteks yang menjadi objek hukum tersebut. Dalam hal ini, konteks keindonesiaan merupakan merupakan subjek dan sekaligus objek fikih dalam menemukan hukum Islam baru selaras dengan kebutuhan hukum umat Islam di Indonesia. Kondisi ini juga sebagai upaya untuk membersihkan fikih dari budaya non-Indonesia. maka tawaran metodologi fikih Indonesia dengan menggunakan pendekatan multidisipliner dengan melakukan integrasi-interkoneksi secara sistemik, sehingga ditemukan teori kebenaran dalam melaksanakan fikih Indonesia. Fakta berikutnya, bahwa fikih sebagai ilmu, tidak dapat dilepaskan dalam konteks sosial budaya tertentu dan mengandung nilai-nilai universal yang akan selalu relevan untuk setiap zaman dan tempat sesuai dengan maqāsşid al-syarī'ah dan sekaligus sebagai filsafat hukum Islam dengan pendekatan sistem (maqashid based-ijtihad).

Menurut Noel J. Coulson, ${ }^{25}$ "hukum Islam" terbagi menjadi dua bagian hukum Tuhan (divine law) dan hukum para faqih (juris law). ${ }^{26}$ Hukum Islam sebagai hukum Tuhan adalah hukum-hukum yang telah ditetapkan oleh Allah dan bersifat absolute dan universal, sedangkan hukum Islam yang dibuat oleh para faqih (fuqoha) adalah hukum Islam yang diperoleh melalui hasil pemahaman manusia yang bersifat historis, relatif dan tidak sakral. ${ }^{27}$ Maka tawaran epistemologi fikih dengan cara mengetahui pesan - pesan hukum dalam Al-Qur'an dan Hadiś sehingga dapat diaplikasikan dalam berbagai perbuatan. Pengkajian tersebut dalam Islam terwujud dalam uşül al-fiqh yang didalamnya memerlukan berbagai macam keilmuan agar tujuan hukum (memelihara agama, jiwa, akal, keturunan dan harta) tetap terjaga. ${ }^{28}$

25 Noel J. Coulson, Conflicts and Tensions in Islamic Jurisprudence (Chicago: The University of Chicago Press, 1969), hlm. 3

${ }^{26}$ Demikian juga John L. Esposito menjelaskan bahwa hukum Islam adalah berasal dari dua sumber utama, yakni wahyu ilahi dan akal manusia. Identitas ganda hukum Islam ini terefleksi dalam dua penunjukan bahasa Arabnya, syari'ah dan fiqh. John L. Esposito, (ed.), Islam Kekuasaan Pemerintah, Doktrin Iman dan Realitas Sosial, terj. M. Khoirul Anam (Jakarta: Inisial Press, 2004), hlm. 161-163; Abdullah Ahmad An-Na'im, Toward an Islamic Reformation; Civil Liberties, Human Rights and International Law (Syracuse: Syracuse University Press, 1990), hlm. 94.

${ }^{27}$ Menurut Mohammad Arkoun, ajaran Islam terbagi dua bagian: at-Turast dengan $\mathrm{T}$ besar yang dianggap sakral, wahyu Allah, obsolute, dan at-Turast dengan $\mathrm{t}$ kecil yang tidak sakral dan bersifat historis karena produk sejarah manusia. Mohammad Arkoun, Al-Fikr al-Islami Qira'ah 'Ilmiyyah, terj. Hasyim Shaleh (Bairut: Markaz al-Inma' al-Qaumi, 1987), hlm. 17 dan 18.

${ }^{28}$ Danusiri, Epistemologi Syara': Mencari Format Baru Fiqh Indonesia (Yogyakarta: Pustaka Pelajar, 2000), hlm. 45-47. 
Konsep memadukan (sintesis) dengan budaya dan adat setempat merupakan pengejawantahan atas praktik pemikiran mazhab fikih scolatik (mazhab fikih klasik). Meminjam pemikiran Arkoun, ${ }^{29}$ bahwa sejarah masyarakat Islam sangat berkaitan dengan sejarah Barat, sehingga tidak ada dikhotomi antara pemikiran Islam dan Barat. Keduanya harus dihargai dan dievaluasi serta dipandang dalam konteks suatu sejarah mengenai kelompok ahli kitab-ahli kitab yang mereformasi universalitas tanpa menghancurkan partikularitas. ${ }^{30}$ Dengan menekankan penting "jaringan hubungan" dari pada fakta atau bahan yang dipertautkan dengan hubungannya dengan manusia, strukturalisme memandang manusia bukan lagi sebagai pusat otonom sebagaimana yang diasumsikan eksistensialisme dan fenomenologi yang tidak bisa diasalkan lagi dari sesuatu yang lain. Sebaliknya, strukturalisme menempatkan manusia sebagai subyek yang tunduk pada struktur (sistem), baik struktur sosial, ekonomi, maupun politik, sehingga subyektifitas merupakan hasil suatu proses strukturalisme yang tidak dikuasasi manusia sendiri.

Tawaran epistemologi di atas, dalam kerangka hendak membangun dasar pembaruan hukum Islam di Indonesia, maka salah satu teori yang layak digunakan sebagai pisau analisis pemikiran pembaruan fikih Indonesia dengan menggunakan pendekatan ilmu-ilmu sosial dan filsafat yang relevan dengan konteks lokalitas dan keindonesiaan.Mengingat hukum Islam sebagai suatu tatanan hidup memiliki posisi yang amat penting, karena didalamnya tersimpan berbagai kebutuhan dan ajaran yang berkenaan dengan umat manusia. Namun manusia yang memiliki kemampuan terbatas tidak semua dapat mengartikan maksud dan tujuan hukum Islam yang mendalam agar mampu memahami isi teks wahyu secara benar dan selaras dengan konteks sosialnya.

Realitas dan konteks masyarakat Muslim Indonesia adalah masyarakat yang plural karena terdiri dari berbagai jenis suku dan budaya. Mereka juga berada dalam daerah geografis yang berbeda beda karena Indonesia merupakan negara kepulauan yang sangat luas.

Hukum Islam sebagai suatu pranata sosial memiliki dua fungsi yaitu sebagai kontrol sosial serta nilai baru dan proses perubahan sosial. Pada fungsi yang pertama, hukum Islam ditempatkan sebagai kontrol sekaligus social engineering terhadap keberadaan suatu masyarakat.

29 Mohammad Arkoun, Nalar Islami dan nalar Modern: Berbagai Tantangan dan Jalan Baru, terj. Rahayu S. Hidayat (Jakarta: INIS, 1994). Hlm. 5

30 Robert D. Lee, "Foreword", dalam: Mohammed Arkoun, Rethingking Islam: Common Questions Uncommon Answere (Boulder ; westview Press, 1994), hlm.x 
Sedangkan fungsi yang kedua, hukum Islam merupakan produk sejarah yang diletakkan sebagai justifikasi terhadap tuntutan perubahan sosial, budaya dan politik. Oleh sebab itu, hukum Islam karakter Indonesia dituntut mampu memberikan jawaban terhadap setiap permasalahan yang muncul tanpa kehilangan dasar - dasarnya. Sebab, apabila tidak terwujud, hukum Islam akan mengalami kemandulan fungsi sehingga menyebabkannya kehilangan aktualitas. ${ }^{31}$

Dalam menjawab terhadap permasalahan hukum Islam di Indonesia sebagai objek studi terhadap fikih yang bersumber dari AlQur'an dengan menggunakan pendekatan dalam memahami Al-Qur'an - dalam hal ini teks menuju konteks- sebagai hubungan yang lekat bersama melalui penafsiran atau hermeneutika. Masih permasalahan di analisis menggunakan metode deduktif, induktif, komperatif bersifat integratif melalui sintetik analisis, ${ }^{32}$ dan kajian struktural transenden. ${ }^{33}$ Epistemologi modern selalu membedakan antara subjek dan objek pengetahuan, sedangkan epistemologi kontemporer tidak memisahkan antara subjek dan objek. ${ }^{34}$ Sehingga epistemologi merupakan salah satu cabang ilmu filsafat yang secara khusus berbicara tentang teori ilmu pengetahuan hukum Islam (fikih) dengan memperhatikan sosio-historis perjalanan hukum Islam oleh Wael B. Hallaq, ${ }^{35}$ ini dikonstruksi menjadi tiga fase, yaitu fase otoritas, fase kontinyuitas, dan fase perubahan. sejarah hukum Islam dari fase ke fase lainnya membutuhkan waktu berabad-abad lamanya. Perubahan yang terjadi tidak secara revolutif, dan terjadi dialektika pemikiran manusia yang bergumul dengan ruang dan waktunya.

${ }^{31}$ Imam Syaukani, Rekonstruksi Epistemologi Hukum Islam Indonesia dan Relevansinya Bagi Pembangunan Hukum Nasional (Jakarta: PT Raja Grafindo Persada, 2006), hlm. 22-23.

32 Toshihiko, God and Man in the Koran: Semantics of the Koranic Weltanschaung (1964); TheConcepts of Belief in Islamic Theology. A Semantics of Iman and Islam (1965), dan Ethico-Religious Concepts in the Quran (1966), lihat Kuntowijoyo, Islam sebagai Ilmu : Epistemologi, Metodologi, dan Etika (Yogyakarta: Tiara Wacara, 2006), hlm. 12.

${ }^{33}$ Kuntowijoyo, Islam sebagai Ilmu...., hlm. 27-47

34 Milton K. Munitz, Contemporary Analytic Philosophy (New York: Macmillan Publishing, 1981), hlm. 4-5.

35 Sejarah pertumbuhan dan perkembangan hukum Islam direkam oleh Hallaq dalam sebuah buku Authority, Continuity, and Change in Islamic Law, Cambridge : Cambrigde Universty Press, 2001, hlm. 47-52; lihat dan bandingkan dengan Noel J. Coulson, Comflicts and Tensions in Islamic Jurisprudence (Chicago: The University of Chicago Press, 1969), hlm. 3 


\section{Kesimpulan}

Dari uraian tersebut dapat disimpulkan bahwa karakteristik hukum Islam di Indonesia sangatlah dominan diwarnai oleh kepribadian Arab dan lekat pada Mazhab Syafi'i. Ini dapat dilihat dari kitab-kitab yang dipakai sebagai rujukan kebanyakan fikih-fikih Syafi'iyah. Kondisi tersebut perlu dicarikan jalan agar tidak selalu terpaku pada fikih yang berlatar belakang Timur Tengah (Arab) sehingga lahir hukum Islam yang lebih fresh berkepribadian dan berkarakter sesuai kondisi sosio-kultural Indonesia. Dengan demikian, epistemologi fikih dan hasil-hasilnya akan cocok dengan keadaan dan kebutuhan masyarakat yang mengitarinya. Interpretasi ulang atas teks wahyu diperlukan harmonisasi dengan konteks sosio-ilmiah berbasis realitas sosial. Fikih (hukum Islam) sebagai produk peradaban pemikiran umat Islam harus mampu menjawab dan dapat memenuhi keadilan sesuai ruang dan waktu kehidupan manusia sebagai subjek dan objek hukum Islam. Dengan demikian, konstruksi epsietmologi fikih Indonesia tetap pada konsep contuniety and change atas perubahan dan dinamika umat Islam Indonesia. 


\section{Daftar Pustaka}

A. Qodri Azizy, Eklektisisme Hukum Nasional: Kompetisi Antara Hukum Islam dan Hukum Umum, Yogyakarta: Gama Media, 2002.

Abdullah Ahmed An-Na'im, 1994, Dekonstruksi Syari'ah : Wacana Kebebasan Sipil, Hak Asasi Manusia, dan Hubungan Internasional dalam Islam, Yogjakarta : LKiS.

Abdurrahman Wahid, dkk., Kontroversi Pemikiran Islam di Indonesia, PT Remaja Rosdakarya, 1993.

Abbas Hammi Mintaredja, Teori-Teori Epistemologi Common sense, Yogyakarta: Paradigma, 2003.

Abu Ameenah Bilal Philips, Evolusi Fiqih, penerj. Ginus Partadiredja, Sumedang: Anjana Pustaka, 2007.

Achmad El Ghandur, Perspektif Hukum Islam; Sebuah Pengantar, Ma'mun Muhammad Mura'I, penj., Yogyakarta: Pustaka Fahima, 2006.

Ali Harb, Nalar Kritis Islam Kontemporer, Yogyakarta: IRCiSoD, 2012.

Amin Abdullah, Islamic Studies di Perguruan Tinggi: Pendekatan Integratif-Interkonektif, Yogyakarta: Pustaka pelajar, 2006.

--, (ed.), Antologi Studi Islam : Teori dan Metodologi, Yogyakarta: Dipa PTA IAIN Sunan Kalijaga Yogyakarta, 2000.

--, Paradigma al-ternatif Pengembangan ushul Fiqh dan Dampaknya pada Fiqh Kontemporer, dalam Ainul Rafiq, (ed), Mazhab Jokja: Menggagas Paradigma Ushul Fiqih Kontemporer, (Yogyakarta: Fakultas Syari'ah IAIN Sunan Kalijaga dan Arruz Press, 2002.

Agus Moh. Najib, Evolusi Syari'ah: Ikhtiar Mohamoud Mohammad Taha Bagi Pembentukan Hukum Islam Kontemporer, Yogyakarta: Pesantren Nawesea Press, 2007.

Anwar, Samsul , Epistemologi Hukum Islam, Probabilitas dan Kepastian, dalam Kearah filsafat Indonesia (ed). Yudian W Asmin, Yogyakarta: Forum Studi Hukum Islam.Fakultas Syari'ah IAIN Yogyakarta, 1994.

Ainurrofiq (ed.), "Mazhab Jogya": Menggagas Paradigma Ushul Fiqh Kontemporer, Yogyakarta: Ar-Ruzz Press dan Fakultas Syari'ah IAIN Suka, 2002.

Abdurrahman Wahid, 1975, Hukum Islam sebagai Penunjang Pembangunan, Prisma No. 4 1985, Pengembangan Fiqh yang Kontekstual, Pesantren. No. 2 Vol. II , 1997, Nilai-nilai Normatif dan reaktualisasi Ajaran Islam. Pengantar untuk Buku Ensiklopedi Ijmak. terj. Sahal Mahfudz dan Mustafa Bisri, Jakarta: Pustaka Firdaus.

Ahmad Rafiq, 1998, Kecenderungan PembaharuanPemikiran Hukum Islam di Indonesia tahun 1970-1990-an : sebuah Kajian Metodologi. Laporan Penelitian Individual IAIN Walisango Semarang.

------------, 1995, Hukum Islam di Indonesia, Jakarta : RajaGrofindo Persada 2001. Pembaruan Hukum Islam di Indonesia, Yogjakarta: Gama Media

Akh. Minhaji, 1999., Reorientasi Kajian Ushul Fiqh, Al-Jami'ah Journal of Islamic Studies. No. 63/VI.

Musyrifah Sunanto, Sejarah Peradaban Islam, Jakarta: RajaGrafindo Persada, 2005.

Khaled M. Abou El Fadl, Atas Nama Tuhan: dari Fikih Otoriter ke Fikih Otoritatif, perjen, R. Cecep Lukman Yasin, Jakarta: Serambi Ilmu Semesta, 2004.

Kazuo Shimogaki, Kiri antara Islam Modernisme dan Postmodernisme : Telaah Kritis atas Pemikiran Hasan Hanafi, Yogyakarta: LKiS, 1994.

Muhyar Fanani, Metode Studi Islam : Aplikasi Sosiologi Pengetahuan Sebagai Cara Pandang, Yogyakarta: Pustaka Pelajar, 2010.

., Fiqh Madani Konstruksi Hukum Islamdi Dunia Modern, Yogyakarta: LKiS, 2010.

Masdar F. Mas'ud, 1991., Agama Keadilan Risalah Zakat (Pajak) Dalam Islam, Jakarta : Pustaka Firdaus

M.Arqoun, Nalar Islami dan nalar Modern: Berbagai tantangan dan Jalan BAru, terj. Rahayu S. Hidayat, Jakarta: INIS, 1994.

Muslih, Muhammad, Filsafat Ilmu KAjian atas Asumsi Dasar, Paradigma dan Kerangka Teori Ilmu Pengetahuan. Yogyakarta: Belukar, 2004. 


\section{Mahfudz Junaedi}

Masdar F. Mas'udi, “Memahami Ajaran Suci dengan Pendekatan Transformatif”, dalam Iqbal Abdul Rauf Saimina (ed.), Polemik Reaktualisasi Ajaran Islam, Jakarta: Pustaka Panjimas, 1988.

Muhammad Roy, Ushul Fiqih Madzhab Aristoteles: Pelacakan Logika Aristoteles Dalam Qiyas Ushul Fiqih, Yogyakarta: Safiria Insania Press, 2004.

Ratno Lukito, Tradisi Hukum Indonesia, Yogyakarta: Teras, 2008.

Sahiron Syamsudin, dkk., 2003, Hermeneutika Al-Qur'an : Mazhab Yogya, Yogjakarta : Islamika.

Yudian Wahyudi, Islam: Percikan Sejarah, Filsafat, Politik, Hukum, dan Pendidikan, Yogyakarta: Pesantren Nawesea Press, 2010.

Ushul Fikih Versus Heurmenetika; Membaca Islam Dari Kanada dan Amerika, Yogyakarta: Nawesea Press, 2007.

Jasser Auda, Maqasid Al-Shariah As Philosophy of Islamic Law: A Systems Aprroach, London: The International Institute of Islamic Thought, 2008 
